\title{
In-vivo isolation of circulating tumor cells in non-small cell lung cancer patients by CellCollector
}

\author{
L. GASIOROWSKI I,„,*, W. DYSZKIEWICZ ${ }^{2, *}$, P. ZIELINSKI ${ }^{2}$ \\ ${ }^{1}$ Department of Intensive Care and Pain Management, Poznan University of Medical Sciences, Poznan, Poland; ${ }^{2}$ Department of Thoracic Surgery, \\ Poznan University of Medical Sciences, Poznan, Poland \\ ${ }^{*}$ Correspondence: lgasior@ump.edu.pl \\ ${ }^{*}$ Contributed equally to this work.
}

Received July 31, 2016 / Accepted April 20, 2017

\begin{abstract}
In non-small cell lung cancer (NSCLC) circulating tumor cells (CTCs) can provide information on patient prognosis and treatment efficacy. Currently CTCs are mostly isolated in vitro from small volumes of patient blood samples. The aim of the study was to assess a medical device for in vivo isolation of CTCs directly from the blood of NSCLC patients. The device was inserted in a cubital vein through a standard cannula for thirty minutes. The interaction of target CTCs with the CellCollector was mediated by an antibody directed against the epithelial cell adhesion molecule. There were 60 applications of the wire in 48 stage I-IIIB NSCLC patients and 12 non-cancer patients. The device was well tolerated in all applications without side effects. We obtained in vivo isolation of CTCs in 32 of 34 NSCLC patients (94.1\%) with a median (range) of 13 (0-300) CTCs. In the non-cancer patients, no CTCs were detected. The safety and efficacy of an in vivo CTC detection method directly from the bloodstream of patients with NSCLC has been demonstrated. This proof of concept study may have important clinical implications, as the implementation of the device into clinical practice may improve early detection, prognosis and therapy monitoring of NSCLC patients.
\end{abstract}

Key words: circulating tumor cells, lung cancer, cancer early detection, cancer diagnosis, cancer screening

Lung cancer remains the most common cause of cancer related deaths worldwide [1]. Despite ongoing refinements in diagnosis [2] and treatment, the survival rates of patients with lung cancer have remained virtually unchanged for the past 20 years. Additionally, non-small lung cancer (NSCLC) is a particularly challenging disease because of the lack of a reliable tumor marker [3]. Combined with the poor survival which is mainly attributable to the lack of effective treatment for systemic disease, and the fact that over two thirds of the patients have metastases, the personalized medicine is at present one of the most challenging goals in innovative cancer therapy [4, 5]. As many tumor cells are distinct on the molecular level [6], and modern drugs target selected molecular pathways, the goal still remains to identify those patients, who might benefit from a certain drug $[4,5]$. Therefore, the isolation of circulating tumor cells (CTCs) from the blood of patients with cancer has been promising [7] and it has shown that pro- and posttreatment CTCs counts were associated with poor prognosis in lung cancer patients [8].
CTC characterization is a rapidly developing research area that could reveal novel drug targets and shed more light on the mechanisms of metastasis development [9]. Over the past decade, several in vitro methodological approaches to detect rare CTCs have been reported $[8,10]$. Currently, only CellSearch ${ }^{\circledR}$ (Veridex, Raritan, NJ) has been FDA approved although not recommended for routine clinical use in lung cancer. The epithelial antibody-coated magnetic bead isolation system is at present used by most studies which allowed the quantification of CTCs from the blood of breast, colon and prostate cancer patients [11]. However, all the detection systems have been naturally limited by the blood volume that can be obtained from the patient [12]. As a result, these methods have yet a relatively low sensitivity, and only in a part of patients with very advanced cancer stages, CTCs can be detected in their blood samples [13].

To overcome the limitations of a small sample volume, an in vivo CellCollector ${ }^{\circledast}$ (GILUPI GmbH, Potsdam, Germany) was developed. It offers a possibility of capturing CTCs in transit 
within the circulation of cancer patients - Figure 1 [14]. Like in ex vivo approaches, the identification of CTCs is based on the phenotypic differences between CTCs of epithelial and cells of hematopoietic origin using markers specific to each population.

In this study, we analyze the correlation of CTCs enumeration directly from the bloodstream of potentially operable NSCLC patients with clinical and pathological features of the tumors resected during surgery.

\section{Materials and methods}

Study design. This was a single-institution prospective study conducted at the Department of Thoracic Surgery at Poznan University of Medical Science in Poland between March 2010 and January 2012. 48 patients were enrolled in the study on the basis of preoperative diagnosis of NSCLC. This patient group consisted of 36 males and 12 females with a mean age of 61.8 years $(\mathrm{SD} \pm 7.0)$. All patients were admitted to the Department and scheduled to be operated electively with a curative intent. The patients' characteristics can be found in Table 1 .

Additionally, the study included 12 subjects as a control group. Those patients were admitted to the Department on an elective basis for various diagnostic procedures such as mediastinoscopy or Video-assisted Thoracoscopic Surgery

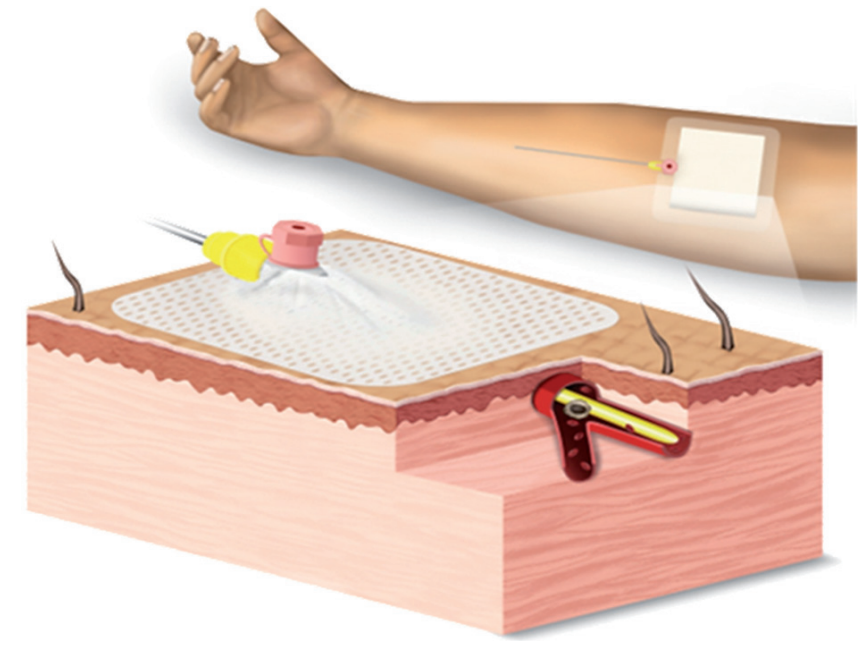

Figure 1. The CellCollector application - diagram

(VATS) without any suspicion of malignancy. This group was younger (mean age $45.3 \mathrm{SD} \pm 15.9$ ) and consisted of 11 males (92\%) and 1 woman (8\%).

All the study patients underwent elective thoracic surgery, which was done most frequently one day after

Table 1. Characteristics of patients with diagnosed NSCLC and CTC enumeration with the CellCollector

\begin{tabular}{|c|c|c|c|c|}
\hline $\begin{array}{l}\text { Subgroup based on histological or } \\
\text { molecular test or tumor stage of NSCLC }\end{array}$ & $\begin{array}{c}\text { Number of patients included } \\
\mathrm{N}(\%) \\
\end{array}$ & Patients with no CTCs & Patients with $<5$ CTCs & Patients with $\geq 5$ CTCs \\
\hline All patients & 34 & $2(6 \%)$ & $7(21 \%)$ & $25(73 \%)$ \\
\hline Male & 24 & $2(8 \%)$ & $5(21 \%)$ & $17(71 \%)$ \\
\hline Female & 10 & 0 & $2(20 \%)$ & $8(80 \%)$ \\
\hline \multicolumn{5}{|l|}{ Age } \\
\hline$<60$ & 15 & $2(13 \%)$ & $3(20 \%)$ & $10(67 \%)$ \\
\hline$\geq 60$ & 19 & 0 & $4(21 \%)$ & $15(79 \%)$ \\
\hline Histological Classification & 34 & & & \\
\hline Squamous Cell Cancer & $22(65 \%)$ & $2(9 \%)$ & $5(23 \%)$ & $15(68 \%)$ \\
\hline Adenocarcinoma & $8(23 \%)$ & 0 & $2(25 \%)$ & $6(75 \%)$ \\
\hline NSCLC (NOS) & $2(6 \%)$ & 0 & 0 & $2(100 \%)$ \\
\hline Large Cell Carcinoma & $1(3 \%)$ & 0 & 0 & $1(100 \%)$ \\
\hline Papillary Cell Carcinoma & $1(3 \%)$ & 0 & 0 & $1(100 \%)$ \\
\hline Tumor stage & 34 & & & \\
\hline T1 No Mo & $3(9 \%)$ & - & $1(33 \%)$ & $2(67 \%)$ \\
\hline T1 N1 M0 & $1(3 \%)$ & - & - & $1(100 \%)$ \\
\hline T2 No M0 & $8(23 \%)$ & $1(12 \%)$ & $2(25 \%)$ & $5(63 \%)$ \\
\hline T2 N1 M0 & $8(23 \%)$ & 0 & $2(25 \%)$ & $6(75 \%)$ \\
\hline T2 N2 M0 & $3(9 \%)$ & 0 & $1(33 \%)$ & $2(67 \%)$ \\
\hline T2 N/A M0 & $1(3 \%)$ & 0 & 0 & $1(100 \%)$ \\
\hline T3 N0 M1 & $1(3 \%)$ & 0 & 0 & $1(100 \%)$ \\
\hline T3 N1 M0 & $3(9 \%)$ & $1(33 \%)$ & 0 & $2(67 \%)$ \\
\hline T3 N2 M0 & $1(3 \%)$ & 0 & 0 & $1(100 \%)$ \\
\hline T4 N2 M0 & $2(6 \%)$ & 0 & $1(50 \%)$ & $1(50 \%)$ \\
\hline$T x N+M 0$ & $2(6 \%)$ & 0 & 0 & $2(100 \%)$ \\
\hline Unknown & $1(3 \%)$ & 0 & 0 & $1(100 \%)$ \\
\hline
\end{tabular}




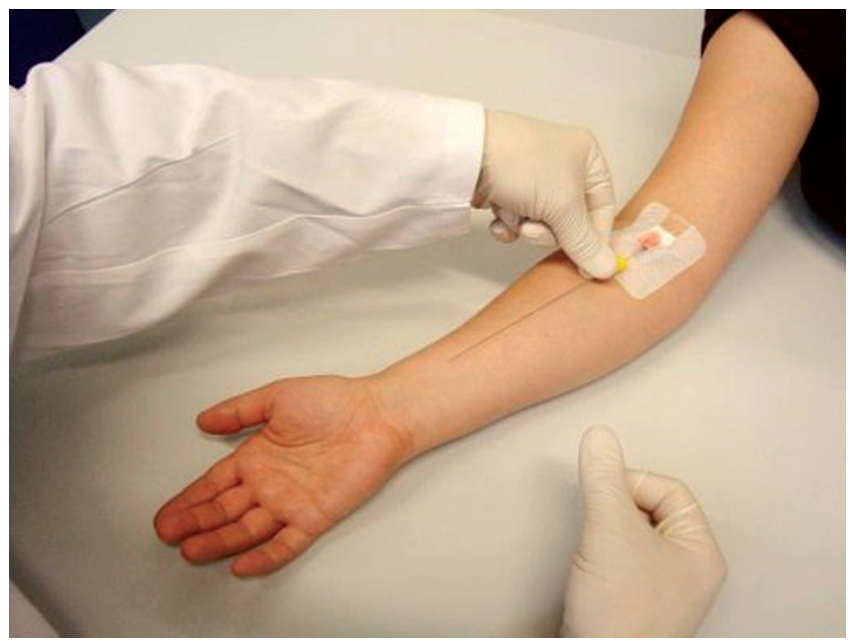

Figure 2. The CellCollector application for 30 minutes before the surgical procedure

the CellCollector ${ }^{\oplus}$ application. All the surgeries were performed with a curative intent, however in three patients no radical surgery was feasible and it was terminated by a positive mediastinoscopy ( 2 cases) or exploratory thoracotomy. Additionally, in one patient the surgery was cancelled secondary to underlying conditions. The most common resection type was lobectomy or bilobectomy (27 patients) followed by pneumonectomy (17 patients). The high pneumonectomy rate in this paper is secondary to a selection-bias. The patients selected for the study had a pre-operative pathologically-confirmed diagnosis. Therefore, they had a tendency to be in more advanced stages, increasing the pneumonectomy rates.

All subjects from the control group underwent various diagnostic procedures such as mediastinoscopy or VATS. The exclusion criteria for both groups were prior thoracic surgery, psychiatric disturbances, any allergies, history of anaphylactic reactions, auto-immunological disease (Goodpasture syndrome, systemic lupus erythematosus, rheumatoid arthritis, sarcoidosis, Sjögren syndrome, scleroderma, positive ANCA antibodies), immunodeficiences, and infections with hepatitis viruses, tuberculosis, CMV, syphilis or toxoplasmosis. Moreover, patients with neoadjuvant chemotherapy were also excluded.

The informed consent was obtained from all the patients. The entire study was approved by local Internal Review Board as well as required government institution (The Office for Registration of Medicinal Products, Medical Devices and Biocidal Products, Warsaw, Poland) and registered at ISRCTN (ISRCTN10403616).

Application of the CellCollector and CTC evaluation. The preoperative analysis of CTCs was performed using the CellCollector, the development of which is described in detail elsewhere (14). Briefly, it is based on a sterile stainless steel medical wire, partially covered with a $2 \mu \mathrm{m}$ gold and a $2-10 \mu \mathrm{m}$ hydrogel layer. To this, an antibody specific against EpCAM (HEA 125) is covalently coupled. The device was inserted through a standard iv cannula and was placed for 30 minutes at least 12 hours prior to surgery into a cubital vein of the patient. The device was fixated to the cannula, and the wire was slowly pushed forward into the lumen, until the activated surface reached $2 \mathrm{~cm}$ into the vein, which was confirmed by outside marks (Figure 2).

After the removal of the device, the device was briefly washed in a phosphate-buffered saline solution followed by incubation in $2 \%$ serum albumin for 30 minutes. The characterization of the CTCs isolated with the CellCollector was done by immunofluorescence analysis. The cells on the wire were labeled with anti EpCAM-FITC moAb (Acris Antibodies, Herford, Germany). To confirm the CTCs epithelial cell origin and exclude leukocyte derivation, the immunohistochemical staining against EpCAM as well as CD45 for negative cell selection was performed. In order to exclude artifact and cell debris, the nuclei were stained with 4,6-diamidino-2-phenylindole (DAPI). Immunocytochemistry images of CTCs were obtained with an Axio Imager. Alm microscope equipped with an AxioCam digital camera and AxioVision 4.6 software (Zeiss, Jena, Germany). The criteria for the identification of CTCs were adapted to those reported in other studies $[12,14,15]$. A cell was counted as a CTC, if its morphological features and staining patterns were consistent with that of an epithelial cell. The following criteria were used for identification: the cells must possibly have an intact morphology, they can be polymorphic (large cell bodies, irregular cell shapes, several cells together / piles etc.), nuclear staining must be positive (Hoechst positive), the cells have to be negative for CD45 and positive for EpCAM, and the diameter should be $\geq 4 \mu \mathrm{m}$. Cells were counted by different operators who were blinded to the patient's history. All results are given as the number of CTCs per CellCollector ${ }^{\circ}$

Statistical analysis. Spearman's correlation coefficient was used to analyze associations between cell counts and other patient features such as clinical stage, age, etc. The differences were considered significant when a p value was less than 0.05 . The statistical analysis was calculated using STATISTICA ver. 10 (StatSoft, Tulsa, OK) software.

\section{Results}

In vivo application of the device. The medical device was inserted into the cubital vein of 48 patients with NSCLC, of whom 12 patients received the device twice. To test for specificity, the medical wire was also inserted into 12 patient volunteers without cancer diagnosis, resulting in total of 60 applications. All the patients tolerated the device insertion without any adverse events. One patient had a hematoma related to the insertion of the cannula, another one was dizzy after the application, having overdosed his antihypertensive medicine. Subjects and investigators assessed the handling and discomfort of the CellCollector application similar to 
that of the iv cannula alone. The clinical information is given in Table 1.

Enumeration data was available for 41 of 60 subjects of the study cohort. The remaining data of 19 patients were sent to an different testing facility and were used for a different study. Additionally, one subject of the control group was excluded after consenting (exclusion criteria sarcoidosis). Of these 41 patients, 34 had NSCLC and 7 were patients without cancer (enumeration data of four patients not available). 32 of 34 (94.1\%) NSCLC patients had at least one CTC on the wire, and 25 of $34(73.5 \%)$ had at least 5 CTCs. None of the 7 control patients had CTCs on the device (100\% specificity) (Figure 3A). The median (range) CTC number was 13 (0-300) cells per device. Figure 4 shows examples of EpCAM positive CTCs captured by the device.

Staging of patients. CTCs were detectable in stage IA to IIIB of the NSCLC patients (Figure 5A). For 4 of the 34 patients with enumeration data the size of the primary tumor was difficult to measure and a definite staging was not possible. The detailed characteristics and the respective number of CTCs captured in vivo with the device are shown in Table 1 . The device detected $\geq 5$ CTCs in ( 25 out of 34 ) $73 \%$ of the patients.

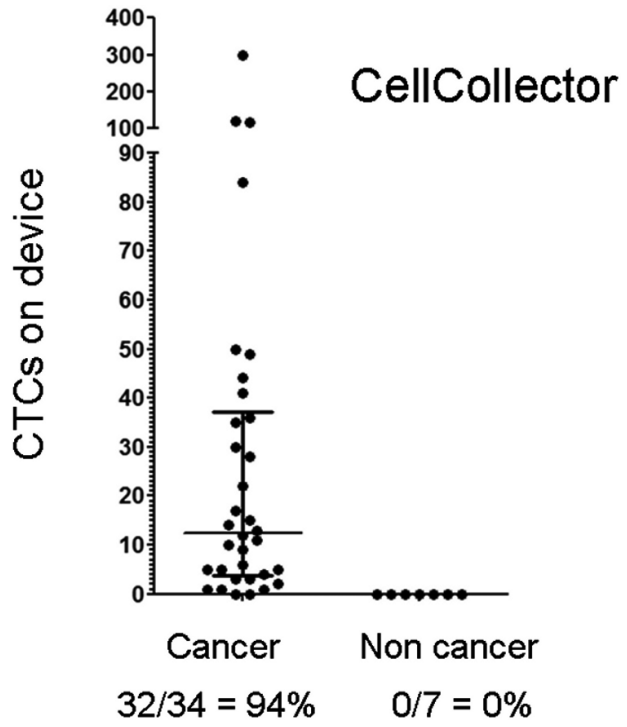

Figure 3. CTC enumeration in cancer and non-cancer patients. Scatterplot of all 41 CellCollector applications. At least one CTC was detected in 32 out of 34 NSCLC patients (94\%) and none CTC in the 7 surgical control patients. (Mean \pm SEM)
OVERLAY
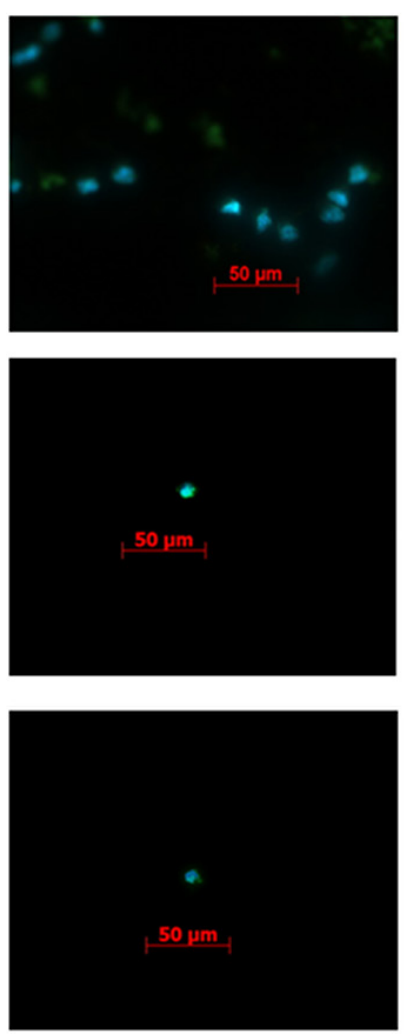

DAPI
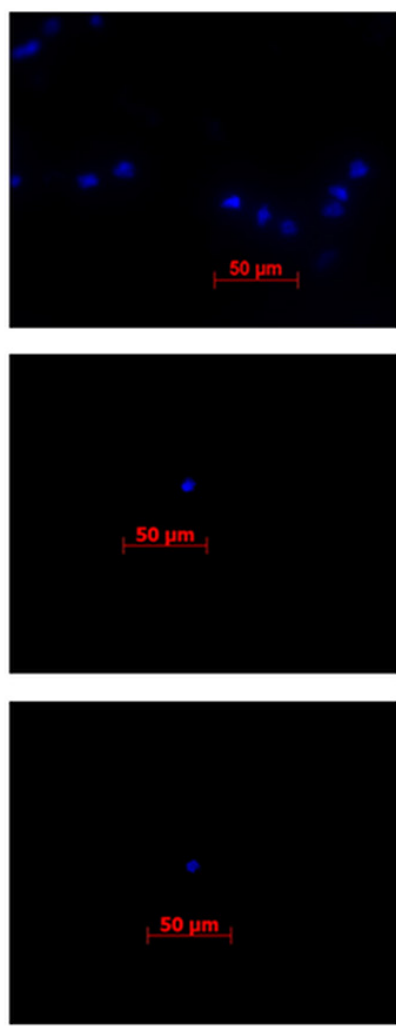

EpCAM
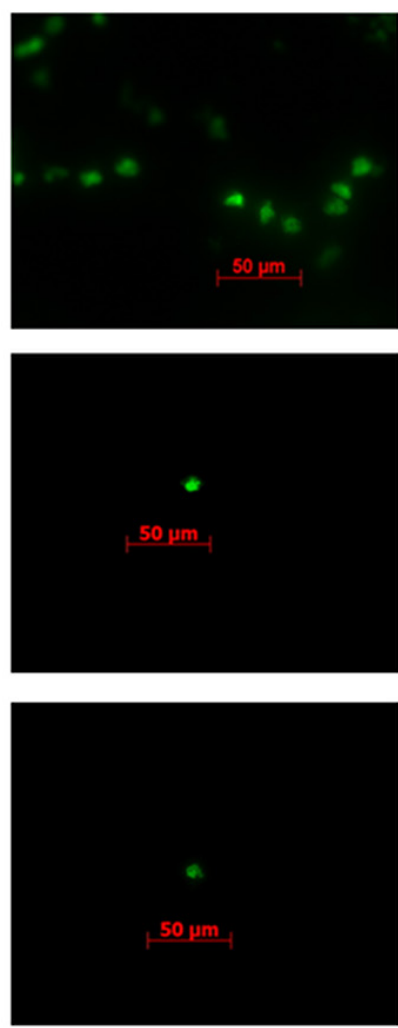

CD45
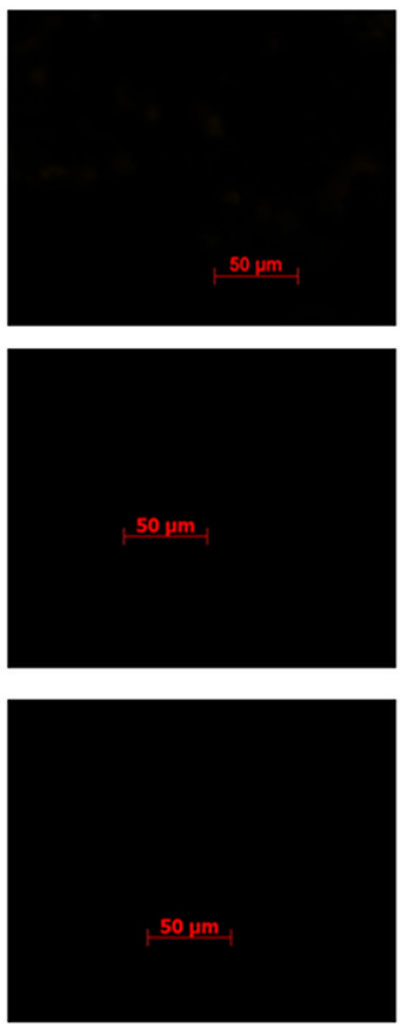

Figure 4. Immunocytochemistry analysis of CTCs captured in vivo with the CellCollector in the blood of NSCLC patients. The CTCs were identified and enumerated via positive EpCAM and DAPI staining and negative CD45 staining (respective green, blue and red staining in top panels, incl. overlay), size and morphological characteristics. CTC examples represent 3 different NSCLC patients. 
The number of cells detected by the CellCollector did not correlate with the pathology type or grading (Table 2). Also patients demographic, as gender or side of the tumor, did not statistically correlate with the CTC count (Table 2). Similarly, age or tumor sizes did not depend on the cells detected (Figure 5B and C). As far as cancer staging is concerned, the number of cells correlated with more advanced clinical stage but finally did not reach statistical significance $(p=0.06)$. It is possible that with bigger study groups this statistical significance would be reached. In addition, the type of surgery was not significant.
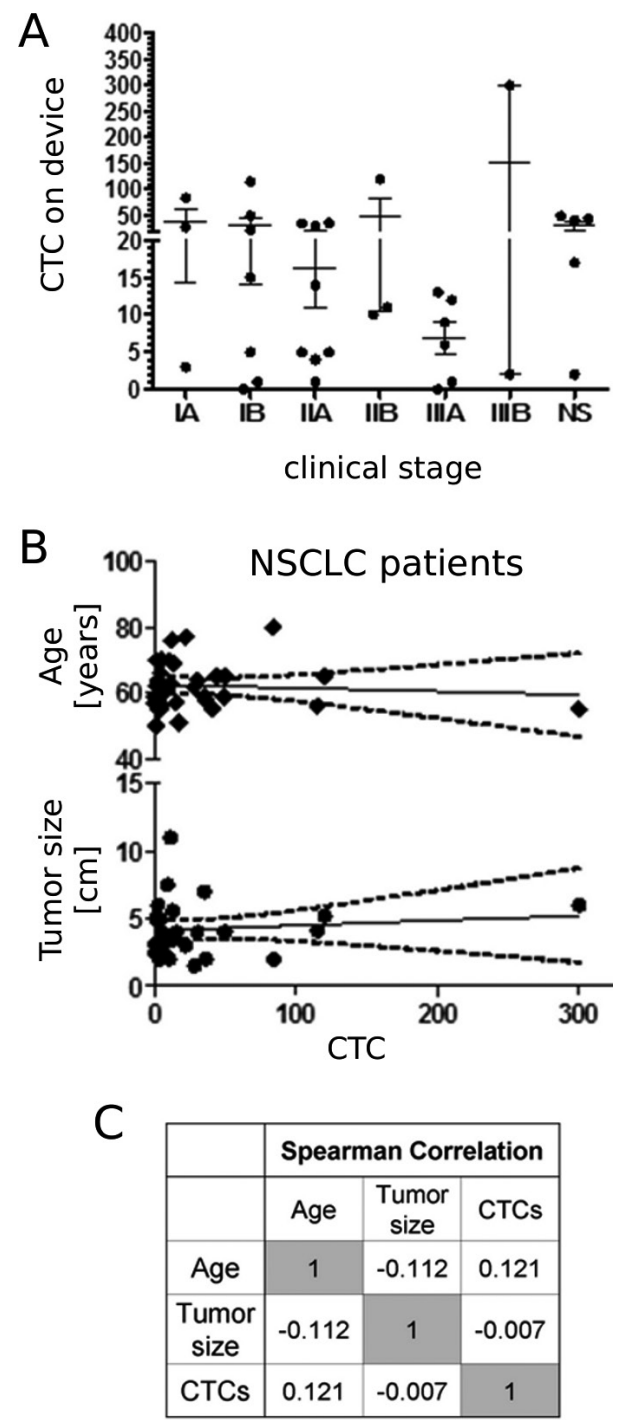

Figure 5. Correlation of CTC enumerations with NSCLC staging, tumor size and age. A) Enumeration of CTCs according to lung cancer staging. CTCs could be detected in stages IA to IIIB and show no correlation to number of CTC isolated in each group. (Mean \pm SEM). NS=No Clinical Stage could be assigned. B) Linear regression of CTC enumeration with tumor size and age. Due to age and tumor size the isolated CTCs did not correlate as also seen in the C) statistical correlations of CTCs with tumor size and age.

\section{Discussion}

The idea of spreading cancer cells through the blood stream and initiating distant metastases has been present for many years. Although currently the evidence for number of circulating tumor cells correlating with metastatic potential is not solid [16. 17], the concept of detecting and quantifying those cells seems to be very promising. Unfortunately, an important limitation of CTC detection seems to be low sensitivity and poor specificity of ex vivo recognition [10]. The role of CTCs in cancer metastasis, and the minimal invasive monitoring of CTCs as biomarkers of either sensitivity or acquired resistance to new cancer therapies has been examined in several studies $[5,18]$. Different methods have been applied in the past to detect occult CTCs in patients with various types of carcinomas $[19,20]$.

Results of CTC characterization have been sometimes different, based on technical characteristics such as marker- and method-related specificity and sensitivity. We evaluate a relatively new method, which offers the advantage of an in vivo application and hence access to many more CTCs than conventional ex vivo methods. This is a first study of CellCollector application in patients with early lung cancer. We show here that it can be applied to NSCLC detecting CTCs in the blood of $94 \%$ patients. In a study by Gorges et al [21], the authors inserted the device twice in patients with locally advanced or metastatic small and non-small cell lung cancer. In this study, the results showed the CTC detection rate of $90 \%$ of patients.

Overall, the CTCs detected with the CellCollector met the selection criteria reported in the literature (8), but it has to be stressed that to date no unified CTC staining protocol exists and most approaches vary in particulars, like staining, counterstaining or cell size. The high sensitivity of the CellCollector in these patients may be surprising, although the concept of an early shedding of CTCs into the circulation is now well established [18] and the early spread of tumor cells remains sometimes undetected even by high-resolution imaging technologies. In these cases, the device would offer the possibility of an early detection of CTCs before the onset of overt metastasis, contributing to an improved identification of patients in need of additional anticancer therapy. Furthermore, the usage of the CellCollector as a tool for early detection of lung cancer can be easily conceivable. With new screening guidelines recommending low dose CT scanning, the wire may be an adjunct decision maker as to which subset of patients from the screened population should be scanned. Additionally, obtaining specific cells may be a form of a 'liquid biopsy' and provide clinicians with a preliminary diagnosis.

We confirmed that the circulating tumor cells may be caught in as early as lung cancer stage IA. Surprisingly, the number of cells caught by the CellCollector did not correlate with the NSCLC subtype. No correlation was found between number of CTCs, and staging. Similar observations are also shown in studies by Okumura et al. and Krebs et al. [10, 22, 23]. However with bigger patient groups it is likely that this number would 
Table 2. CTCs and clinical data analysis

\begin{tabular}{|c|c|c|c|c|c|c|c|c|}
\hline \multicolumn{3}{|c|}{ Patients characteristics } & \multicolumn{6}{|c|}{ CTC data } \\
\hline Categories & & $\mathrm{N}(\%)$ & Mean & 1st Quartile & Median & 3rd Quartile & $\mathrm{SD}$ & $P$ value \\
\hline \multirow{2}{*}{ Gender $(\mathrm{n}=34)$} & male & $24(71 \%)$ & 39.6 & 4.4 & 16.0 & 45.7 & 65.2 & \multirow{2}{*}{0.283} \\
\hline & female & $10(29 \%)$ & 13.0 & 4.8 & 11.5 & 15.8 & 14.1 & \\
\hline \multirow{5}{*}{ Tumor $(\mathrm{n}=32)$} & $\mathrm{T} 1$ & $4(12.5 \%)$ & 38.0 & 12.8 & 32.0 & 64.0 & 34.2 & \multirow{5}{*}{0.610} \\
\hline & $\mathrm{T} 2 \mathrm{a}$ & $17(53 \%)$ & 20.0 & 2.8 & 11.0 & 32.9 & 29.0 & \\
\hline & $\mathrm{T} 2 \mathrm{~b}$ & $4(12.5 \%)$ & 39.0 & 5.6 & 37.2 & 82.0 & 56.4 & \\
\hline & $\mathrm{T} 3$ & $5(16 \%)$ & 8.0 & 4.0 & 9.0 & 11.7 & 5.1 & \\
\hline & $\mathrm{T} 4$ & $2(6 \%)$ & 153.5 & 7.0 & 153.5 & 300.0 & 207.2 & \\
\hline \multirow{3}{*}{$\begin{array}{l}\text { Nodal Involvement } \\
(\mathrm{n}=32)\end{array}$} & N0 & $12(37.5 \%)$ & 21.0 & 1.7 & 15.0 & 40.0 & 31.0 & \multirow{3}{*}{0.188} \\
\hline & N1 & $12(37.5 \%)$ & 20.0 & 4.4 & 7.5 & 23.3 & 33.0 & \\
\hline & N2 & $8(25 \%)$ & 55.0 & 7.8 & 13.0 & 39.5 & 100.3 & \\
\hline Clinical stage & All stages & & & & & & & 0.063 \\
\hline \multirow{2}{*}{ Grading $(n=23)$} & $\mathrm{G} 2$ & $14(61 \%)$ & 18.4 & 3.3 & 10.5 & 29.2 & 27.8 & \multirow[t]{2}{*}{0.418} \\
\hline & G3 & $9(39 \%$ & 40.9 & 2.3 & 22.0 & 78.3 & 46.2 & \\
\hline \multirow{5}{*}{ Histology $(\mathrm{n}=34)$} & Squamous Cell Cancer & $22(65 \%)$ & 38.8 & 5.0 & 28.0 & 124.0 & 68.3 & \multirow{5}{*}{0.845} \\
\hline & Adenocarcinoma & $8(23 \%)$ & 19.8 & 3.3 & 7.0 & 29.4 & 19.8 & \\
\hline & NSCLC (NOS) & $2(6 \%)$ & 29.0 & 2.3 & 29.0 & 46.0 & 16.9 & \\
\hline & Large Cell Carcinoma & $1(3 \%)$ & - & & & & - & \\
\hline & Papillary Cell Carcinoma & $1(3 \%)$ & - & & & & & \\
\hline
\end{tabular}

reach statistical significance. It is also not entirely clear why the cell number range is frequently different within even the same tumor type, size and clinical stage. This is either secondary to genetic diversity and moreover intratumor heterogeneity of the tumor [24] or may be an independent prognostic feature.

The number of CTCs before surgery is an independent predictor of progression-free survival and overall survival in patients with lung cancer $[10,25,26]$ and other cancers, like breast cancer [25]. We do not have long term follow-up data on patients yet, we did not investigate the prognostic impact of the CTCs. The proposed threshold (5 CTCs) of the CellSearch ${ }^{\oplus}$ method may not be applicable to this more sensitive in vivo method, and other cut-offs might be needed.

Our study also has some limitations. First, we focus here on the enumeration of CTCs and lack the subsequent molecular analysis of the isolated CTCs. The continuous molecular monitoring of a patient's tumor during chemotherapy therapy may be important in the future, as the molecular pattern of primary tumor and metastasis may be distinct $[6,28]$ and may evolve under therapy [9]. Subsequent studies need to address this issue for the CellCollector and need to demonstrate that besides enumeration, captured CTCs are sufficiently intact for downstream applications, like PCR or FISH. Also, we lack the prognostic data to assess the value of CTC enumeration for the present study population. However, here the methodology seems to be less relevant, and results of other CTC trials may advance the field and applicability also for other techniques, like the in vivo CellCollector approach.

In this report we demonstrate safety and efficacy of an in vivo capturing method for CTCs directly from the circulation of patients with NSCLC. Whilst the device was well toler- ated, the high sensitivity in the small cohort tested justifies further clinical trials in cancer patients. Further studies have to demonstrate the integrity of the CTCs for subsequent molecular diagnostics. Additionally, another challenge remains the continuous follow-up of lung cancer patients after completion of therapy in order to detect early signs of cancer recurrence. Likewise, there is no single convenient and cost effective method to monitor this group of patients. This application can help select patients for chemotherapy at early stage of cancer recurrence and is likely to be one important link in the chain of personalized diagnosis and treatment of cancer patients.

Acknowledgements: Part of this work is supported by a grant from the Bundesministerium für Bildung und Forschung (BMBF), Förderkennzeichen 01EZ 0863 and Ministerium für Wirtschaft des Landes Brandenburg und der EU, Förderkennzeichen 80135447.

\section{References}

[1] JEMAL A, BRAY F, CENTER MM, FERLAY J, WARD E et al. Global cancer statistics. CA Cancer J Clin 2011; 61: 69-90. https://doi.org/10.3322/caac.20107

[2] BOUILLEZ A, RAJABI H, PITRODA S, JIN C, ALAM M et al. Inhibition of MUC1-C Suppresses MYC Expression and Attenuates Malignant Growth in KRAS Mutant Lung Adenocarcinomas. Cancer Res 2016; 76: 1538-1548. https:// doi.org/10.1158/0008-5472.CAN-15-1804

[3] VAN'T WESTEINDE SC, VAN KLAVEREN RJ. Screening and early detection of lung cancer. Cancer J 2011; 17: 3-10. https://doi.org/10.1097/PPO.0b013e3182099319 
[4] DOROSHOW JH, PARCHMENT RE. Oncologic phase 0 trials incorporating clinical pharmacodynamics: from concept to patient. Clin Cancer Res 2008; 14: 3658-3663. https://doi. org/10.1158/1078-0432.CCR-07-4562

[5] KUHLMANN J, WENSING G. The applications of biomarkers in early clinical drug development to improve decision-making processes. Curr Clin Pharmacol 2006; 1: 185-191. https://doi. org/10.2174/157488406776872578

[6] KAN Z, JAISWAL BS, STINSON J, JANAKIRAMAN V, BHATT D et al. Diverse somatic mutation patterns and pathway alterations in human cancers. Nature 2010; 466: 869-873. https://doi.org/10.1038/nature09208

[7] MAHESWARAN S, SEQUIST LV, NAGRATH S, ULKUS L, BRANNIGAN B et al. Detection of mutations in EGFR in circulating lung-cancer cells. N Engl J Med 2008; 359: 366-377. https://doi.org/10.1056/NEJMoa0800668

[8] MA XL, XIAO ZL, LIU L, LIU XX, NIE W et al. Meta-analysis of circulating tumor cells as a prognostic marker in lung cancer. Asian Pac J Cancer Prev 2012; 13: 1137-1144. https://doi. org/10.7314/APJCP.2012.13.4.1137

[9] HOU JM, KREBS M, WARD T, SLOANE R, PRIEST L et al. Circulating tumor cells as a window on metastasis biology in lung cancer. Am J Pathol 2011; 178: 989-996. https://doi. org/10.1016/j.ajpath.2010.12.003

[10] KREBS MG, SLOANE R, PRIEST L. LANCASHIRE L, HOU $J$ et al. Evaluation and prognostic significance of circulating tumor cells in patients with non-small-cell lung cancer. J Clin Oncol 2011; 29: 1556-1563. https://doi.org/10.1200/ LCO.2010.28.7045

[11] COHEN SJ, PUNT CJ, IANNOTTI N, SAIDMAN BH, SABBATH KD et al. Relationship of circulating tumor cells to tumor response, progression-free survival, and overall survival in patients with metastatic colorectal cancer. J Clin Oncol 2008; 26: 3213-3221. https://doi.org/10.1200/ JCO.2007.15.8923

[12] TIBBE AG, MILLER MC, TERSTAPPEN LW. Statistical considerations for enumeration of circulating tumor cells. Cytometry A 2007; 71: 154-162. https://doi.org/10.1002/ cyto.a.20369

[13] ALLARD WJ, MATERA J, MiLLER MC, REPOLLET M, CONNELLY MC et al. Tumor cells circulate in the peripheral blood of all major carcinomas but not in healthy subjects or patients with nonmalignant diseases. Clin Cancer Res 2004; 10: 6897-6904. https://doi.org/10.1158/1078-0432.CCR-04$\underline{0378}$

[14] SAUCEDO-ZENI N, MEWES S, NIESTROJ R, GASIOROWSKI L, MURAWA D et al. A novel method for the in vivo isolation of circulating tumor cells from peripheral blood of cancer patients using a functionalized and structured medical wire. Int J Oncol 2012; 41: 1241-1250. https://doi.org/10.3892/ijo.2012.1557

[15] LARSON CJ, MORENO JG, PIENTA KJ, GROSS S, REPOLLET $\mathrm{M}$ et al. Apoptosis of circulating tumor cells in prostate cancer patients. Cytometry A 2004; 62: 46-53. https://doi. org/10.1002/cyto.a.20073

[16] KIM P, LIU X, LEE T, LIU L, BARHAM R et al. Highly sensitive proximity mediated immunoassay reveals HER2 status conversion in the circulating tumor cells of metastatic breast cancer patients. Proteome Sci 2011; 9: 75. https://doi. org/10.1186/1477-5956-9-75

[17] WENDEL M, BAZHENOVA L, BOSHUIZEN R, KOLATKAR A, HONNATTI $M$ et al. Fluid biopsy for circulating tumor cell identification in patients with early-and late-stage nonsmall cell lung cancer: a glimpse into lung cancer biology. Phys Biol 2012; 9: 016005. https://doi.org/10.1088/14783967/9/1/016005

[18] STOECKLEIN NH, KLEIN CA. Genetic disparity between primary tumours, disseminated tumour cells, and manifest metastasis. Int J Cancer 2010; 126: 589-598. https://doi. org/10.1002/ijc.24916

[19] KREBS MG, HOU JM, WARD TH, BLACKHALL FH, DIVE C. Circulating tumour cells: their utility in cancer management and predicting outcomes. Ther Adv Med Oncol 2010; 2: 351-365. https://doi.org/10.1177/1758834010378414

[20] YU M, STOTT S, TONER M, MAHESWARAN S, HABER DA. Circulating tumor cells: approaches to isolation and characterization. J Cell Biol 2011; 192: 373-382. https://doi. org/10.1083/jcb.201010021

[21] GORGES TM, PENKALLA N, SCHALK T, JOOSSE SA, RIETHDORF S et al. Enumeration and Molecular Characterization of Tumor Cells in Lung Cancer Patients Using a Novel In Vivo Device for Capturing Circulating Tumor Cells. Clin Cancer Res 2016 22: 2197-2206. https://doi.org/10.1158/10780432.CCR-15-1416

[22] KREBS MG, HOU JM, SLOANE R, LANCASHIRE L, PRIEST L et al. Analysis of circulating tumor cells in patients with nonsmall cell lung cancer using epithelial marker-dependent and -independent approaches. J Thorac Oncol 2012; 7: 306-315. https://doi.org/10.1097/JTO.0b013e31823c5c16

[23] OKUMURA Y, TANAKA F, YONEDA K, HASHIMOTO $\mathrm{M}$, TAKUWA $\mathrm{T}$ et al. Circulating tumor cells in pulmonary venous blood of primary lung cancer patients. Ann Thorac Surg 2009; 87: 1669-1675.

[24] GERASHCHENKO TS1, DENISOV EV, LITVIAKOV NV,ZAVYALOVA MV, VTORUSHIN SV et al. Biochemistry (Mosc) 2013; 78: 1201. https://doi.org/10.1134/S0006297913110011

[25] HOU JM, KREBS MG, LANCASHIRE L, SLOANE R, BACKEN A et al. Clinical significance and molecular characteristics of circulating tumor cells and circulating tumor microemboli in patients with small-cell lung cancer. J Clin Oncol 2012; 30: 525-532. https://doi.org/10.1200/JCO.2010.33.3716

[26] YOON SO, KIM YT, JUNG KC, JEON YK, KIM BH et al. TTF-1 mRNA-positive circulating tumor cells in the peripheral blood predict poor prognosis in surgically resected non-small cell lung cancer patients. Lung Cancer 2011; 71: 209-216. https://doi.org/10.1016/j.lungcan.2010.04.017

[27] CRISTOFANILLI M, HAYES DF, BUDD GT, ELLIS MJ, STOPECK A et al. Circulating tumor cells: a novel prognostic factor for newly diagnosed metastatic breast cancer. J Clin Oncol 2005; 23: 1420-1430. https://doi.org/10.1200/ LCO.2005.08.140

[28] O'FLAHERTY JD, GRAY S, RICHARD D, FENNELL D, O'LEARY JJ et al. Circulating tumour cells, their role in metastasis and their clinical utility in lung cancer. Lung Cancer 2012; 76: 19-25. https://doi.org/10.1016/j.lungcan.2011.10.018 